\title{
Tourism Affordances as a Research Lens
}

\section{Introduction}

We propose that the concept of affordances can be useful in tourism research, for two reasons. First, it integrates recent theoretical progress in a range of related fields, across tourism, recreation and leisure research. Second, it provides new practical insights into the tourism industry, notably the importance of comparing tourists at home and on holiday.

The term affordance is a theoretical conceptualisation of a common vernacular phrase, room to manoeuvre. It represents the interaction between an individual's capabilities and their circumstances. It originated in ecology, to describe the opportunities available to different species in different environments. It was taken up in sports science and outdoor recreation, focussing on training to improve capabilities. It was expanded into the social sciences, through recognition that individual circumstances include social as well as physical context. Each of these phases is reviewed briefly below. We propose to apply it broadly in tourism.

A general model of tourism affordances integrates several previous theoretical concepts, including: tourism freedoms (Caruana \& Crane 2011); leisure or tourism constraints (Crawford, Jackson, \& Godbey 1991; Nyaupane \& Andereck 2008); and social affordances (Akcaoglu \& Lee 2019). We argue that freedoms and constraints differ between home and holiday; and that tourists gain expanded affordances relative to home life, depending on activities, destination countries and cultures, and individual circumstances. Tourism can therefore be analysed as a mechanism to extend affordances. This suggests that we need to study tourists at home, as well as while on holiday.

\section{Affordances Integrate Freedoms and Constraints}

The affordances framework integrates theoretical analyses of freedoms and constraints. Tourist freedoms include both liberation, freedom from everyday routine; and license, freedom to engage in behaviour forbidden at home. The liberation aspect has been analysed as escape (Crouch 1994; Dann 1977; Uysal \& Jurowski 1994; Vidon \& Rickley 2018); the licence aspect as hedonism (Calver \& Page 2013; Carr 2002; Malone, McCabe, \& Smith 2014; Shakeela \& Weaver 2018). Freedoms differ between destinations, affecting both inbound and outbound tourism (Gholipour, Tajaddini, \& Al-mulali 2014; Liu, Li, \& Fu 2016; Saha, Su, \& Campbell 2017). There are also events, venues and activities in domestic tourism that offer enhanced freedoms, either physical (Kane \& Tucker 2004), or social (Griffin et al. 2016; Li, Chung, \& Kim 2016; Kearns, Collins, \& Bates 2017; Mikkelson \& Cohen 2015). Tourism research has used a freedoms framework, since a holiday involves a choice and change from the norms of home (Xiao et al. 2013).

Leisure studies research has used a constraints framework (Crawford et al. 1991; Jackson, Crawford, \& Godbey 1993). Leisure time is free choice, but choices may be restricted. The constraints model has been adopted, adapted, applied and critiqued very widely (Alexandris et al. 2017; Godbey, Crawford, \& Shen 2010; Ito, Kono, \& Walker 2018; Kazeminia, Del Chiappa, \& Jafari 2015; Kono, Ito, \& Loucks-Atkinson 2018; Kyle \& Jun 2015; Lai, Li, \& Harrill 2013; Samdahl \& Jekubovich 1997; Scott \& Lee 2018). One such adaptation is the tourism constraints model (Chen, Chen \& Okumus 2013; Kazeminia et al. 2015; Nyaupane \& Andereck 2008). 


\section{Evolution of Affordances Frameworks}

The concept of affordances originated in ecology, under the former name of ecological dynamics (Gibson 1979; Chemero 2003, Chemero \& Turley 2004; Shaw, Kinsella-Shaw, \& Mace 2019). It has been adopted extensively in sport and recreation (Araujo \& Davids 2009, 2011; Brymer, Davids, \& Mallabon 2014; Davids et al. 2013; Fajen, Riley, \& Turvey 2009; Lopez-Rivera \& Gonzalez-Badillo 2012; Rantala 2010). Affordances can include social or moral aspects (Akcaoglu \& Lee 2018; Molz 2013; Usher \& Gomez 2018). These have been analysed for communications (Cabiddu, De Carlo, \& Piccoli 2014; Fox \& McEwan 2017), and education (Akcaoglu \& Lee 2018; Sharma-Brymer et al. 2018). Two tourism studies have suggested that individuals may have different affordances within the same experience, either adventurous (Peacock et al., 2017) or cultural (Ackerman, 2018).

\section{Individual, Social and Material Affordances}

Both freedoms and constraints models recognise individual, social, and material categories. The material or structural category includes economics and logistics, such as visas, infrastructure, travel and accommodation. These are analysed in tourism economics, planning and geography (Font \& Hindley 2017; Seetaram, Forsyth, \& Dwyer 2016). The social or interpersonal category includes opinions of leisure and tourism activities held by: coparticipants in those activities; friends or relatives; colleagues or workmates; and the institutional structures of society, such as law enforcement personnel. These are addressed as host-guest and client-guide interactions, tour group dynamics, and social capital (Lawton \& Weaver 2015; Needham et al. 2017). The individual or intrapersonal category includes personal desires, capabilities, and beliefs, studied as tourist motivations and experiences. Every individual has freedoms and constraints in each category.

We propose here that individual, social and material categories of tourism freedoms and constraints may be seen as three types of affordances. Each type of affordance can differ between individuals, and between their countries and societies. Wealthy individuals have greater material freedoms, and fewer material constraints. Individuals with strong religious adherence may have greater internal constraints and fewer freedoms, in regard to some more hedonistic activities. Individuals with demands and social pressures, from family members and social circles, must negotiate social freedoms for tourism. Every country determines behaviours that are legally and socially acceptable for its residents and domestic tourists. In most countries (Demir \& Gozgor 2018), though not necessarily all (Shakeela \& Weaver 2018), these rules are also applied to international inbound tourists.

We propose that tourism opportunities for any individual represent the intersection of their individual, social and material affordances: i.e., room to manoeuvre between each of these three sets of constraints and freedoms. For individuals, the three affordances are theoretically independent. Wealthy individuals may or may not have greater social as well as material affordances; strongly religious individuals may or may not have reduced social as well as individual affordances. At broader social scale, however, the three affordances are likely to be correlated, because wealth, social circles, and individual beliefs are all strongly influenced by socioeconomic circumstances and cultural context. 


\section{Tourism as a Mechanism to Expand Affordances}

We can analyse tourists as seeking different expansions of their affordances at home. Some want to visit friends and relatives, whom they cannot see whilst at home. Some want to buy clothing or other items more cheaply, or from a greater range, than are available at home. Some want to take part in experiences that are either entirely novel, or in new places, or with greater opportunities, than at home. Some want new social opportunities, from meeting likeminded individuals engaged in the same activities, whom they would not meet at home. All of these involve expansion of affordances, from home to holidays. Equally, some types of tourism involve a trade-off of affordances, with opportunities balanced by restrictions. For example, nature or adventure tourists travelling internationally, may accept greater cultural restrictions as the price of new experiences.

An affordance expansion that is powerfully desired, eg through an emotional or addictive component, can command a higher price premium than one that is purely utilitarian (Buckley 2015). Expansions of individual affordances may be valued more highly than expansions of material affordances, but this has not been tested. Escape-style expansions of hedonistic social affordances may be more valuable to people who live in restrictive societies. VFRstyle expansions of family-related social affordances may be more valuable in cultures where family interactions are frequent and important. There are thus many tourism research issues where new insights could become available through an affordances lens.

There is little research to date, contrasting the behaviours of the same individuals at home and on holiday respectively. There is extensive research on both liberation and licence aspects of tourism freedoms, but with a focus on the destination, not comparison between destination and origin for the same individual tourists. The tourism affordances framework can refocus research on tourism motivations and experiences, to grant more explicit recognition to the reasons why tourists choose particular destinations, tours and holidays. Motivational research asks what tourists want to do; behavioural research asks what they actually do. Affordance research could ask more fundamentally, why they do it: what specific affordances in their home, work and domestic life do tourists want to expand whilst on holiday?

\section{Implications and Conclusions}

From a practical perspective, a tourism affordances framework can pinpoint: what contributes most critically to tourist satisfaction; what different tourists are most prepared to pay for; and what tour operators and destinations must make available, to attract clientele with specific origins and interests. As one example, outdoor tour operators offer portfolios of products, some for skilled exponents, others for neophytes (Buckley 2012). The former seek expansion of individual affordances. The latter may want either expanded social opportunities (Buckley 2012), or safe and comfortable access to nature (Peacock et al., 2017). These are different affordances, affecting safety, marketing and management, pricing and profitability. It is therefore valuable to know which affordance most accurately reflects tourists' intentions.

In summary, we conclude that the theoretical concept of affordances, adapted to a tourism context and incorporating tourism freedoms and tourism constraints, can provide a valuable and novel perspective on tourism analysis, with both practical and theoretical implications. In particular, it indicates that tourism research should pay greater attention to tourists at home, as well as on holiday. To achieve this, we shall need to address new and difficult, but not insurmountable, design considerations and ethical concerns. 


\section{REFERENCES}

Ackerman, J. W. 2018. "Meaning-Making in the Course of Action: Affordance Theory at the Pilgrim/Tourist Nexus.” Tourism Geographies, doi: 10.1080/14616688.2018.1505942

Akcaoglu, M., and E. Lee. 2018. "Using Facebook Groups to Support Social Presence in Online Learning." Distance Education 39:1-19.

Alexandris, K., J. Du, D. Funk, and N.D. Theodorakis. 2017. "Leisure Constraints and the Psychological Continuum Model: A Study among Recreational Mountain Skiers." Leisure Studies, 36:670-83.

Araujo, D., and K. Davids. 2009. "Ecological Approaches to Cognition and Action in Sport and Exercise: Ask Not Only What You Do, But Where You Do It." International Journal of Sport Psychology 40:5.

Araujo, D., and K. Davids. 2011. "What Exactly is Acquired During Skill Acquisition?" Journal of Consciousness Studies 18:7-23.

Brymer, E., K. Davids, and L. Mallabon. 2014. "Understanding the Psychological Health and Well-Being Benefits of Physical Activity in Nature: an Ecological Dynamics Analysis." Ecopsychology 6:189-97.

Buckley, R.C. 2012. "Rush as a Key Motivation in Skilled Adventure Tourism: Resolving the Risk Recreation Paradox.” Tourism Management 33:961-70.

Buckley, R.C. 2015. “Adventure Thrills Are Addictive.” Frontiers in Psychology 6:1915.

Cabiddu, F., M. De Carlo, and G. Piccoli. 2014. "Social Media Affordances: Enabling Customer Engagement.” Annals of Tourism Research 48:175-92.

Calver, S. J., and S.J. Page. 2013. "Enlightened Hedonism: Exploring the Relationship of Service Value, Visitor Knowledge and Interest, to Visitor Enjoyment at Heritage Attractions." Tourism Management 39:23-36.

Carr, N. 2002. "The Tourism-Leisure Behavioural Continuum." Annals of Tourism Research 29:972-86.

Caruana, R., and A. Crane. 2011. "Getting Away From It All: Exploring Freedom in Tourism.” Annals of Tourism Research 38:1495-515.

Chemero, A. 2003. “An Outline of a Theory of Affordances.” Ecological Psychology 15:18195.

Chemero, A., and M.T. Turvey. 2007. "Complexity, Hypersets, and the Ecological Perspective on Perception-Action.” Biological Theory 2:23-36. 
Chen, H.J., P.J. Chen, and F. Okumus. 2013. "The Relationship Between Travel Constraints and Destination Image: A Case Study of Brunei.” Tourism Management 35:198-208.

Crawford, D. W., E.L. Jackson, and G. Godbey. 1991. "A Hierarchical Model of Leisure Constraints.” Leisure Sciences 13:309-20.

Crouch, D. 1994. "Home, Escape and Identity: Rural Cultures and Sustainable Tourism." Journal of Sustainable Tourism 2:93-101.

Dann, G. M. 1977. “Anomie, Ego-enhancement and Tourism.” Annals of Tourism Research 4:184-94.

Davids, K., E. Brymer, L. Seifert, and D. Orth. 2013. "A Constraints-Based Approach to the Acquisition of Expertise in Outdoor Adventure Sports." In Complex Systems in Sport, eds. Davids, K., Hristovski, R., Araujo, D., \& Button, C., pp. 332-344. Abingdon: Routledge.

Demir, E., and G. Gozgor. 2018. "Does Freedom of the Press Enhance Inbound Tourism?" Current Issues in Tourism, doi: 10.1080/13683500.2018.1470608

Fajen, B. R., M.A. Riley, and M.T. Turvey. 2009. "Information, Affordances, and the Control of Action in Sport.” International Journal of Sport Psychology 40:79-107.

Font, X., and A. Hindley. 2017. 'Understanding Tourists' Reactance to the Threat of a Loss of Freedom to Travel due to Climate Change: A New Alternative Approach to Encouraging Nuanced Behavioural Change.” Journal of Sustainable Tourism 25:26-42.

Fox, J., and B. McEwan. 2017. "Distinguishing Technologies for Social Interaction: The Perceived Social Affordances of Communication Channels Scale." Communication Monographs 84:298-318.

Gholipour, H.F., R. Tajaddini, and U. Al-mulali. 2014. "Does Personal Freedom Influence Outbound Tourism?” Tourism Management 41:19-25.

Gibson, J. J. 1979. The Ecological Approach to Visual Perception. Boston: Houghton Mifflin.

Godbey, G., D.W. Crawford, and X.S. Shen. 2010. "Assessing Hierarchical Leisure Constraints Theory After Two Decades.” Journal of Leisure Research 42:111-34.

Griffin, C., A. Bengry-Howell, S. Riley, Y. Morey, and I. Szmigin. 2016. "“We Achieve the Impossible': Discourses of Freedom and Escape at Music Festivals and Free Parties.” Journal of Consumer Culture, 1469540516684187.

Ito, E., S. Kono, and G.J. Walker. 2018. "Development of Cross-Culturally Informed Leisure-Time Physical Activity Constraint and Constraint Negotiation Typologies: the Case of Japanese and Euro-Canadian Adults." Leisure Sciences, doi: 10.1080/01490400.2018.1446064

Jackson, E.L., D.W. Crawford, and G. Godbey. 1993. "Negotiation of Leisure Constraints." Leisure Sciences 15:1-11. 
Kane, M.J. and H. Tucker. 2004. "Adventure Tourism: The Freedom to Play With Reality." Tourist Studies 4:217-34.

Kazeminia, A., G. Del Chiappa, and J. Jafari. 2015. "Seniors' Travel Constraints and Their Coping Strategies.” Journal of Travel Research 54:80-93.

Kearns, R., D. Collins, and L. Bates. 2017. “'It's Freedom!': Examining the Motivations and Experiences of Coastal Freedom Campers in New Zealand." Leisure Studies 36:395-408.

Kono, S., E. Ito, and A. Loucks-Atkinson. 2018. "Are Leisure Constraints Models Reflective or Formative? Evidence from Confirmatory Tetrad Analyses." Leisure Sciences, doi: 10.1080/01490400.2018.1474508

Kyle, G., and J. Jun. 2015. "An Alternate Conceptualization of the Leisure Constraints Measurement Model: Formative Structure?” Journal of Leisure Research 47:337-57.

Lai, C., X.R. Li, and R. Harrill. 2013. "Chinese Outbound Tourists' Perceived Constraints to Visiting the United States.” Tourism Management 37:136-46.

Lawton, L.J., and D.B. Weaver. 2015. 'Using Residents' Perceptions Research to Inform Planning and Management for Sustainable Tourism: A Study of the Gold Coast Schoolies Week, A Contentious Tourism Event.” Journal of Sustainable Tourism 23:660-82.

Li, J., Y. Chung, and W.G. Kim. 2016. "Freedom of Choice as a Critical Success Factor in Destination Marketing: Empirical Evidence From a Far-East Gambling City.” Tourism and Hospitality Research 18:321-32.

Liu, X.R., J.J. Li, and Y.D. Fu. 2016. “Antecedents of Tourists' Behavioral Intentions: The Role and Influence of Tourists' Perceived Freedom of Choice, Destination Image, and Satisfaction." Tourism Analysis 21:577-88.

Lopez-Rivera, E., and J.J. Gonzalez-Badillo. 2012. "The Effects of Two Maximum Grip Strength Training Methods Using the Same Effort Duration and Different Edge Depth on Grip Endurance in Elite Climbers." Sports Technology 5:100-10.

Malone, S., S. McCabe, and A.P. Smith. 2014. "The Role of Hedonism in Ethical Tourism." Annals of Tourism Research 44:241-54.

Molz, J.G. 2013. "Social Networking Technologies and The Moral Economy of Alternative Tourism: The Case of Couchsurfing.org." Annals of Tourism Research 43:210-30

Needham, M.D., B.W. Szuster, C. Mora, L. Lesar, and E. Anders. 2017. "Manta Ray Tourism: Interpersonal and Social Values Conflicts, Sanctions, and Management." Journal of Sustainable Tourism 25:1367-84.

Nyaupane, G.P., and K.L. Andereck. 2008. Understanding Travel Constraints: Application and Extension of a Leisure Constraints Model." Journal of Travel Research 46:433-9.

Peacock, S., E. Brymer, K. Davids, and M. Dillon. 2017. “An Ecological Dynamics Perspective on Adventure Tourism.” Tourism Review International 21:307-16. 
Rantala, O. 2010. "Tourist Practices in the Forest." Annals of Tourism Research 37: 249-64.

Saha, S., J.J. Su, and N. Campbell. 2017. "Does Political and Economic Freedom Matter for Inbound Tourism? A Cross-National Panel Data Estimation.” Journal of Travel Research 56:221-34.

Samdahl, D.M., and N.J. Jekubovich. 1997. "A Critique of Leisure Constraints: Comparative Analyses and Understandings.” Journal of Leisure Research 29:430-52.

Scott, D., and K.J. Lee. 2018. "People of Color and Their Constraints to National Parks Visitation." George Wright Forum 35:73-82.

Seetaram, N., P. Forsyth, and L. Dwyer. 2016. "Measuring Price Elasticities of Demand for Outbound Tourism Using Competitiveness Indices.” Annals of Tourism Research 56:65-79.

Shakeela, A., and D. Weaver. 2018. "'Managed Evils' of Hedonistic Tourism in the Maldives: Islamic Social Representations and Their Mediation of Local Social Exchange.” Annals of Tourism Research 71:13-24.

Sharma-Brymer, V., E. Brymer, T. Gray, and K. Davids. 2018. "Affordances Guiding Forest School Practice: the Application of the Ecological Dynamics Approach." Journal of Outdoor and Environmental Education 21:103-15.

Shaw, R.E., J.M. Kinsella-Shaw, and W.M. Mace. 2019. "Affordance Types and Affordance Tokens: Are Gibson's Affordances Trustworthy?” Ecological Psychology 31:49-75.

Usher, L.E., and E. Gómez. 2018. "Female Surfers' Perceptions of Regulatory Constraints and Negotiation Strategies.” Journal of Park \& Recreation Administration 36:149-65.

Uysal, M., and C. Jurowski. 1994. "Testing the Push and Pull Factors." Annals of Tourism Research 21:844-6.

Xiao, H., J. Jafari, P. Cloke, and J. Tribe. 2013. “Annals: 40-40 Vision.” Annals of Tourism Research 40:352-85. 